\title{
Chrysin induces cell growth arrest, apoptosis, and ER stress and inhibits the activation of STAT3 through the generation of ROS in bladder cancer cells
}

\author{
YI XU, YANYUE TONG, JUNJIE YING, ZHANGMING LEI, LIJUN WAN, XIUWEN ZHU, FENG YE, \\ PENGLEI MAO, XINKUAN WU, RENBING PAN, BO PENG, YUKUN LIU and JIANYONG ZHU \\ Department of Urology, Quzhou People's Hospital, Quzhou, Zhejiang 324000, P.R. China
}

Received April 6, 2017; Accepted October 17, 2017

DOI: $10.3892 / \mathrm{ol} .2018 .8522$

\begin{abstract}
Chrysin is a natural flavone that has various biological activities, including antitumor effects. However, the effect of chrysin on bladder cancer cells remains elusive. The present study investigated the effects of chrysin on bladder cancer cells and its underlying mechanisms. The results demonstrated that chrysin induced apoptosis via the intrinsic pathway, as evidenced by activation of caspase- 9 and caspase-3, however not caspase-8. In addition, chrysin reduced the expression of anti-apoptotic B cell lymphoma $(\mathrm{Bcl})$ proteins including $\mathrm{Bcl}-2, \mathrm{Mcl}-1, \mathrm{Bcl}-\mathrm{xl}$, and promoted the protein expression of pro-apoptotic Bcl-2 associated $\mathrm{X}$, apoptosis regulator. Chrysin also induced endoplasmic reticulum stress via activation of the unfolded protein response of PRKR-like endoplasmic reticulum kinase, eIF $2 \alpha$ and activating transcription factor 4 in bladder cancer cells. Additionally, chrysin inhibited the signal transducer and activator of transcription 3 pathway. Furthermore, the generation of reactive oxygen species (ROS) was detected following treatment with chrysin. The ROS scavenger $\mathrm{N}$-acetylcysteine inhibited the antitumor effect of chrysin. Collectively, these results indicate chrysin may act as a promising therapeutic candidate for targeting bladder cancer.
\end{abstract}

\section{Introduction}

Bladder cancer has become a global health issue, as the second most common type of 'tract cancer' in the developed countries, with over 400,000 new cases and 160,000 mortalities worldwide per year (1). At diagnosis, $\sim 30 \%$ of bladder cancer patients have invasive muscle tumor cells, and $10 \%$ of patients have metastatic tumor cells with a poor prognosis (2). Currently, surgical resection, radiation and chemotherapy are common

Correspondence to: Dr Jianyong Zhu, Department of Urology, Quzhou People's Hospital, 2 Zhongloudi, Kecheng, Quzhou, Zhejiang 324000, P.R. China

E-mail: zhujianyongbrave@yeah.net

Key words: chrysin, apoptosis, ER stress, STAT3, ROS, bladder cancer therapeutic strategies used to fight against bladder cancer. However, surgery and the current cisplatin-based combination therapeutic options are limited by the side effects associated with treatment and by some tumor cells eventually developing drug resistance (3). Therefore, it is imperative to develop novel strategies to overcome bladder cancer, including therapies that can be applied in combination with current strategies. Mounting evidence indicates that natural compounds provide a new window of opportunity due to their safety and potential to overcome resistance to chemotherapy (4).

Chrysin (5,7-dihydroxyflavone) is a natural flavone found in multiple plant extracts, such as honey and pollen, that has a wide range of biological activities such as antibacterial, antihypertensive, anti-allergic, anti-inflammatory, and antioxidant effects (5-9). Chrysin is also an active inhibitor of cancer cells. For example, chrysin can induce cell death in various cancer types such as hepatocellular, breast, prostate and pancreatic carcinomas $(10,11)$. In addition, chrysin overcame chemoresistance to cisplatin and Adriamycin in non-small cell lung cancer (NSCLC) cells (8). These findings make chrysin an attractive antitumor agent. However, there is still little knowledge about the effects of chrysin on bladder cancer cells.

In the present study, we observed a stronger cytotoxicity for chrysin against human bladder cancer cells than against non-malignant immortalized urothelial cells. Mechanistically, we showed that chrysin induced apoptosis via the intrinsic pathway. In addition, we demonstrated that chrysin could induce ER stress and suppress the STAT3 signaling pathway, which relies on the generation of ROS.

\section{Materials and methods}

Cell culture and chemicals. The human bladder cancer cell lines T-24 and 5637 and the non-malignant immortalized urothelial SV-HUC-1 cells were purchased from the Shanghai Bank of Cell Culture (Shanghai, China). Cells were cultured in RPMI 1640 medium (Thermo Fisher Scientific, Inc., Waltham, MA, USA) supplemented with $10 \%$ fetal bovine serum plus $100 \mathrm{U} / \mathrm{ml}$ penicillin and $100 \mu \mathrm{g} / \mathrm{ml}$ streptomycin (Thermo Fisher Scientific, Inc.) at $37^{\circ} \mathrm{C}$ in a humidified atmosphere of $5 \% \mathrm{CO}_{2}$. Chrysin (purity $>99 \%$ ) was purchased from Sigma (St. Louis, MO, USA) and dissolved in DMSO. 
3-(4,5-Dimethylthiazol-2yl)-2,5-diphenyltetrazolium bromide (MTT), N-acetyl cysteine (NAC) and DMSO were purchased from Sigma. Z-LEHD-FMK, Z-DEVD-FMK and Z-IETD-FMK were purchased from Abcam (Cambridge, CA, USA). All other chemicals were obtained from Sigma.

MTT assay. Cells were cultured in $96-$ well plates at a density of $1 \times 10^{4}$ cells/well and treated with various concentrations of chrysin. After treatment for the indicated time, MTT was added, followed by another $4 \mathrm{~h}$ incubation. The OD at $570 \mathrm{~nm}$ was read using a microplate reader (Biotek, Winooski, VT, USA). Experiments were carried out in triplicate and were repeated separately three times.

Apoptosis assay. Apoptotic cell death was examined by the analysis of DNA fragmentation as previously described (12). Briefly, cells were collected after treatment. Nicoletti buffer [sodium citrate $0.1 \%$ (w/v) containing $0.1 \%$ Triton X-100 (w/v) and propidium iodide $50 \mathrm{ng} / \mathrm{ml}$ ] was added to the cell pellets and incubated for $2 \mathrm{~h}$ at $4^{\circ} \mathrm{C}$ in the dark room. The fluorescence intensity was then measured with a FACSVerse TM flow cytometer (Beckman Coulter, Fullerton, CA, USA) and analyzed with the FlowJo software (Tree Star, Inc., Ashland, OR, USA). The formula to calculate the apoptosis is as follows: (percentage of treated apoptosis-percentage of spontaneous apoptosis)/(100-percentage of spontaneous apoptosis) x100.

Subcellular fraction purification. The cytosolic fraction was isolated using cytosolic and mitochondrial fraction kits (Beyotime, Shanghai, China) according to the manufacturer's guide.

Western blot analysis. For each sample, cells were lysed using the CHAPS buffer provided by Cell Signaling Technology (Danvers, MA, USA). Protein samples $(20 \mu \mathrm{g})$ were separated on a $10 \%$ SDS-PAGE gel and transferred onto a PVDF membrane (Millipore, Billerica, MA, USA). PVDF membranes were then blocked with 5\% skimmed milk (BYL40422; BD Biosciences, Franklin Lakes, NJ, USA). The following primary antibodies were used at $4^{\circ} \mathrm{C}$ overnight: PERK (cat. no. ab65142; dilution, 1:1,000), EIF2 $\alpha$ (cat. no. ab5369; dilution, 1:1,000; Abcam), GAPDH (cat. no. SAB 2100894; dilution, 1:5,000; Sigma), p-PERK (cat. no. 3179; dilution 1:1,000), p-EIF2 $\alpha$ (cat. no. 3398; dilution, 1:1,000), caspase-3 (cat. no. 9662; dilution 1:1,000), caspase-8 (cat. no. 9746; dilution 1:1,000), caspase-9 (cat. no. 9502; dilution 1:1,000), Bcl-2 (cat. no. 4223; dilution, 1:1,000), Mcl-1 (cat. no. 5453; dilution 1:1,000), Bcl-xl (cat. no. 2762; dilution, 1:1,000), Bax (cat. no. 2774; dilution, 1:1,000), p-STAT3 (cat. no. 9154; dilution, 1:1,000), and STAT3 (cat. no. 4904; dilution 1:1,000) were purchased from Cell Signaling Technology. Then anti-rabbit (cat. no. A0545; dilution, 1:5,000) and anti-mouse (cat. no. M5899; dilution, 1:5,000) HRP-conjucted secondary antibodies (Sigma) were used at room temperature for $1 \mathrm{~h}$. Signals were visualized with ECL reagent (Pierce Biotechnology, Inc., Rockford, IL, USA). Densitometric analysis was performed with Quantity One software (Bio-Rad Laboratories, Richmond, CA, USA).

Caspase activity assays. The activity of caspases was measured using a caspase activity assay kit purchased from
Beyotime (Beijing, China) according to the manufacturer's protocol. The peptides were DEVD-, IETD- and LEHD-p-NA for the caspase-3, -8 and -9 assays, respectively. Briefly, cell lysates were prepared after treatment and incubated with the supplied reaction buffer and the colorimetric substrates at $37^{\circ} \mathrm{C}$ for $2 \mathrm{~h}$ in the dark. Then, the absorbance of the solutions was measured with a Bio Tek microplate reader at $405 \mathrm{~nm}$.

ROS detection. After treatment with chrysin, cells were collected and stained with $15 \mu \mathrm{M}$ DCFH-DA for $30 \mathrm{~min}$, washed with PBS and then evaluated using a FACSVerseTM flow cytometer. Data were analyzed using FlowJo V10 (Tree Star, Inc.).

Statistical analysis. All data values were presented as the mean \pm SD (standard deviation). Statistical comparisons were measured using a one-way analysis of variance (ANOVA) followed by Tukey's test. Statistical analyses were carried out by using SPSS software (SPSS Inc., Chicago, IL, USA). P $<0.05$ was considered to indicate a statistically significant difference.

\section{Results}

Cytotoxic effect of chrysin on bladder cancer cells. To evaluate the cytotoxic effects of chrysin on human bladder cancer cells in vitro, we incubated two human bladder cancer lines, T24 and 5637, with various doses $(20,40,60,80 \mu \mathrm{M})$ of chrysin for $24 \mathrm{~h}$; cell viability was measured using the MTT assay. The results showed that chrysin displayed an antitumor effect in a concentration-dependent manner (Fig. 1A). Then, we treated T24 and 5637 cells with $40 \mu \mathrm{M}$ for various times $(12,24,3648$ h). As shown in Fig. 1B, chrysin also repressed the viability of bladder cancer cells in a time-dependent manner. To examine the cytotoxic effects of chrysin on normal bladder cells, we incubated SV-HUC-1, which is an immortalized non-malignant bladder urothelial cell line, with chrysin. Interestingly, chrysin exerted little toxicity on SV-HUC-1 (Fig. 1A and B). Taken together, these data suggest that chrysin exerts a selective antitumor effect on bladder tumor cells but not on normal cells. T24 cells were selected for further analysis since they were more sensitive to chrysin than the 5637 cells.

Chrysin selectively induces apoptosis in human bladder cells. Then, we asked whether chrysin could induce apoptosis in bladder cancer cells. T24 cells were treated with various doses $(20,40,80 \mu \mathrm{M})$ of chrysin for $24 \mathrm{~h}$, and apoptotic cells were measured using the apoptosis assay as described earlier (12). As shown in Fig. 2A, we found that chrysin induced apoptosis in a dose-dependent manner in T24 cells, while there was little apoptosis in the non-malignant SV-HUC-1 cells. To further investigate the apoptosis induced by chrysin, we used western blotting to measure the protein levels of caspases, which are a family of protease enzymes that play essential roles in apoptosis. We found that chrysin triggers the activation of caspase-3/9 but not caspase- 8 in a dose-dependent manner in T24 cells but not in SV-HUC-1 cells (Fig. 2B). In addition, the activities of caspases were measured by a commercial caspase activity assay kit. In line with the western blot results, the activity of caspase-3/9 but not caspase- 8 was significantly 
A
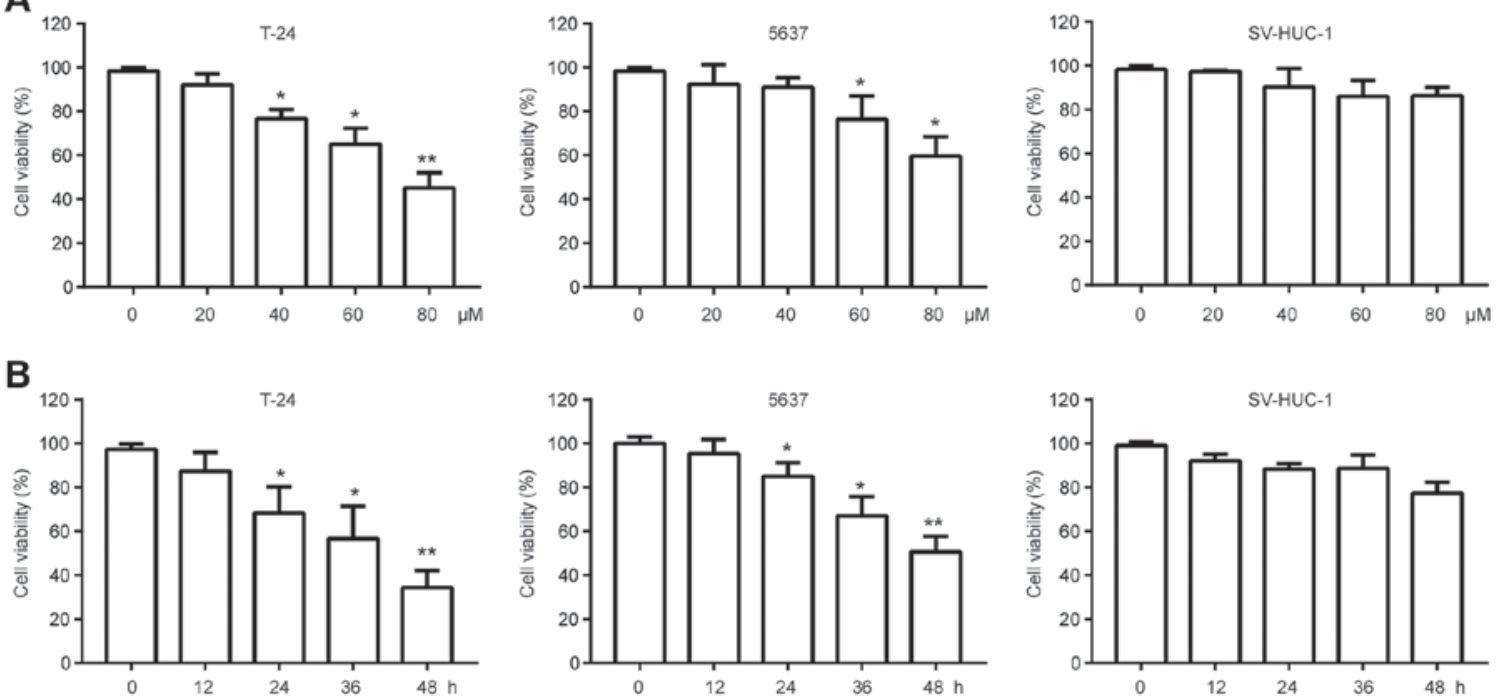

Figure 1. Chrysin inhibits the viability of bladder cancer cells but not non-malignant cells. (A) Bladder cancer cell lines T-24 and 5637 and non-malignant SV-HUC-1 cells were treated with various doses of chrysin for $24 \mathrm{~h}$, then cell viability was measured by the MTT assay. (B) Bladder cancer cell lines T-24 and 5637 and non-malignant SV-HUC-1 cells were treated with $40 \mu \mathrm{M}$ chrysin for various times, then cell viabilities were measured with MTT assay. Data are presented as the mean $\pm \mathrm{SD}(\mathrm{n}=3) .{ }^{*} \mathrm{P}<0.05,{ }^{* *} \mathrm{P}<0.01$ vs. control. MTT, 3-(4,5-Dimethylthiazol-2yl)-2,5-diphenyltetrazolium bromide.

enhanced by chrysin treatment in T24 cells. At the same time, the activity of caspases could not be detected in the SV-HUC-1 cells (Fig. 2C).

Chrysin induces apoptosis via the intrinsic pathway in bladder cancer cells. There are two pathways leading to apoptosis, known as the intrinsic and extrinsic pathways (13). The intrinsic pathway is initiated by caspase-9, while the extrinsic pathway is initiated by caspase-8. Both pathways ultimately rely on the activation of caspase-3. Our observation that caspase- $9 / 3$ but not caspase- 8 was activated after the treatment of chrysin suggested that the induction of apoptosis was via the intrinsic pathway in T24 cells. To further confirm this, various specific caspase inhibitors were used. As indicated in Fig. 3A, the specific caspase-3 inhibitor (Z-DEVD-FMK) and caspase-9 inhibitor (Z-LEHD-FMK) but not the caspase-8 inhibitor (Z-IETD-FMK) could markedly inhibit both the apoptosis-induced by chrysin $(80 \mu \mathrm{M})$ and the chrysin-mediated repression T24 cell viability (Fig. 3A). The intrinsic apoptotic pathway is known to be regulated by the $\mathrm{Bcl}-2$ proteins, which can be divided into anti-apoptotic and pro-apoptotic members (13). Therefore, we asked whether the levels of $\mathrm{Bcl}-2$ proteins were affected after the chrysin treatment. We found that the expressions of the anti-apoptotic proteins Bcl-2, Mcl-1 and Bcl-xl were repressed, while the pro-apoptotic protein Bax was upregulated, by chrysin in a dose-dependent manner (Fig. 3B). Furthermore, we also observed an increase in cytochrome $\mathrm{c}$ and Smac/DIABLO in the cytosol in a dose-dependent manner in T24 cells (Fig. 3C). These findings suggest that chrysin may induce intrinsic apoptosis via the modulation of $\mathrm{Bcl}-2$ proteins.

Chrysin induces ER stress and inhibits the STAT3 pathway in bladder cancer cells. Endoplasmic reticulum (ER) stress plays a critical role in apoptosis induced by different natural flavones or their derivatives (14-16). Therefore, we suspected that the activation of ER stress involved in bladder cancer cell apoptosis may be induced by chrysin. PERK (protein kinase RNA-like endoplasmic reticulum kinase), a type-I ER transmembrane protein, can be activated in response to ER stress (17). PERK activation then directly leads to eIF $2 \alpha$ (eukaryotic initiation factor $2 \alpha$ ) phosphorylation and translation inhibition (18). In addition, ATF4 (activating transcription factor-4) induces the transcription of various target genes during the ER stress response (19). Therefore, PERK-eIF2 $\alpha$-ATF4 axis activation is a hallmark of ER stress. We measured the status of PERK, eIF2 $\alpha$, and ATF4 in T2 4 cells after chrysin treatment. As indicated in Fig. 4, chrysin induces the up-regulation of ATF-4 and the phosphorylation of PERK eIF $2 \alpha$ in T2 4 cells in a dose-dependent manner.

It has been well documented that STAT proteins are involved in the process of apoptosis by regulating the expression of Bcl-2 proteins (20). Constitutively active STAT3 is found in different human cancers. Various flavones have also been found to induce apoptosis via inhibition of STAT3 activation. To further investigate the potential mechanism of the antitumor effect of chrysin, we examined the levels of STAT3 protein. We found that treatment with chrysin reduced the level of phosphorylated STAT3 but not total STAT3 in a dose-dependent manner.

These results suggest that both ER stress and STAT3 may potentially be involved in chrysin-induced apoptosis in T24 cells.

ROS accumulation is associated with the antitumor effect of chrysin. Many studies have indicated that ROS accumulation induced by anti-cancer agents can trigger cell death in different types of cancers. Therefore, we asked whether ROS generation is associated with the antitumor effect of chrysin. We detected intracellular ROS levels after chrysin treatment and found that ROS generation was increased in a dose-dependent manner (Fig. 5A and B). Moreover, we treated T24 cells with chrysin 

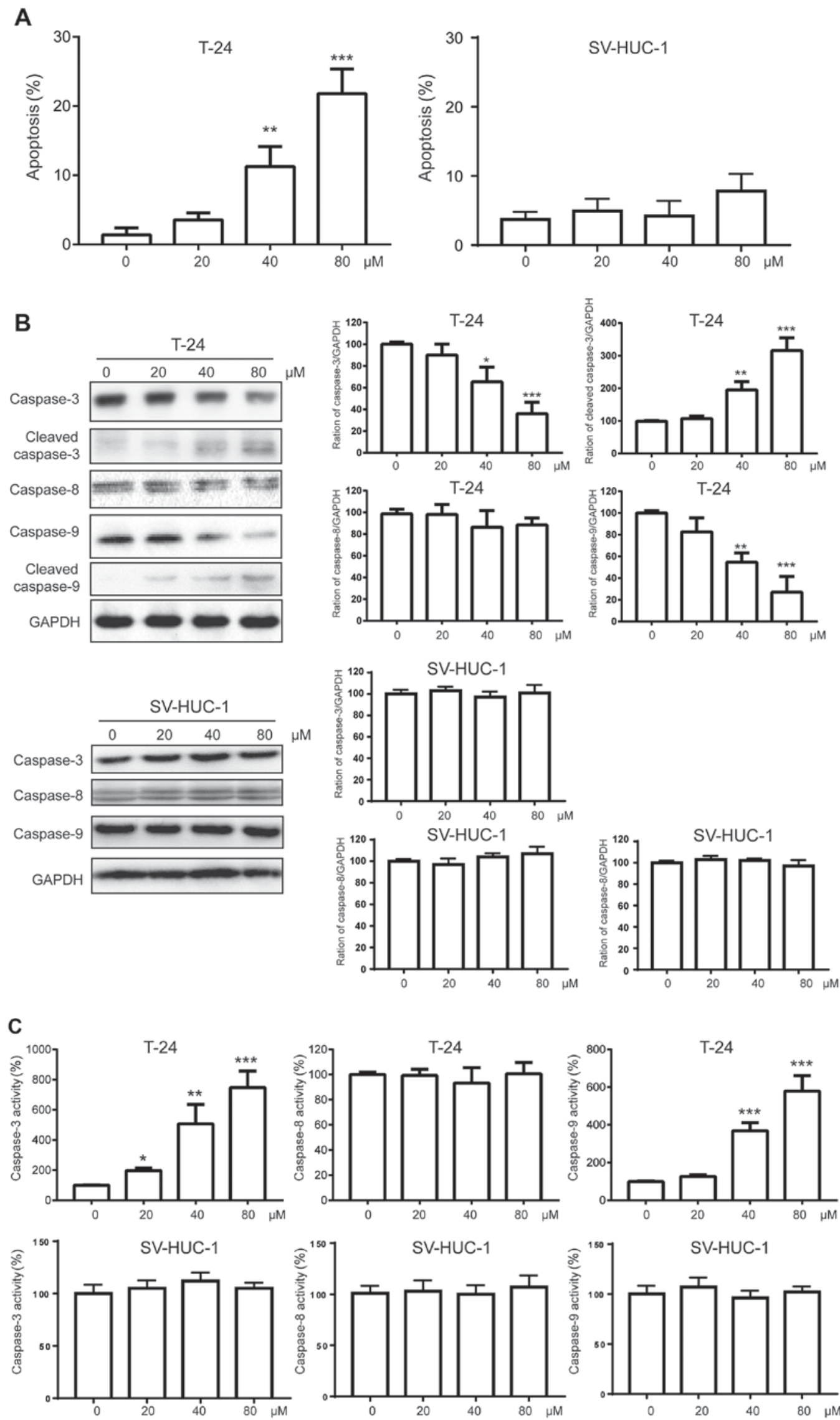

Figure 2. Chrysin induces apoptosis in bladder cancer cells but not non-malignant cells. (A) Human bladder cancer T24 and non-malignant SV-HUC-1 cells were treated with various doses $(0,20,40,80 \mu \mathrm{M})$ of chrysin for $24 \mathrm{~h}$, then cellular apoptosis was measured by flow cytometry. (B) Human bladder cancer cells T24 and SV-HUC-1 cells were treated with various doses $(0,20,40,80 \mu \mathrm{M})$ of chrysin for $24 \mathrm{~h}$, then cellular lysates were subjected to western blot analysis. The band densities of western blots were quantitatively analyzed. (C) Human bladder cancer cells T24 and SV-HUC-1 cells were treated with various doses $(0,20,40,80 \mu \mathrm{M})$ of chrysin for $24 \mathrm{~h}$, then cellular lysates were subjected to caspase activity assays. Data are presented as the mean $\pm \mathrm{SD}(\mathrm{n}=3)$. $\mathrm{P}<0.05$, ${ }^{* *} \mathrm{P}<0.01,{ }^{* * *} \mathrm{P}<0.001$ vs. control. 
A
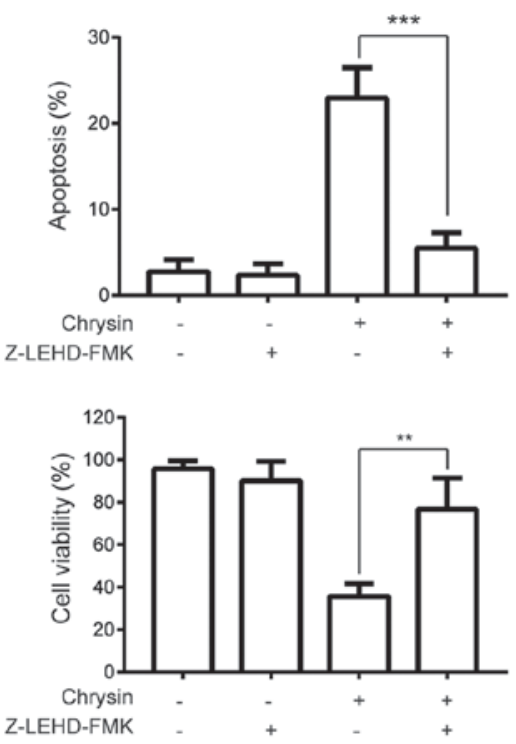
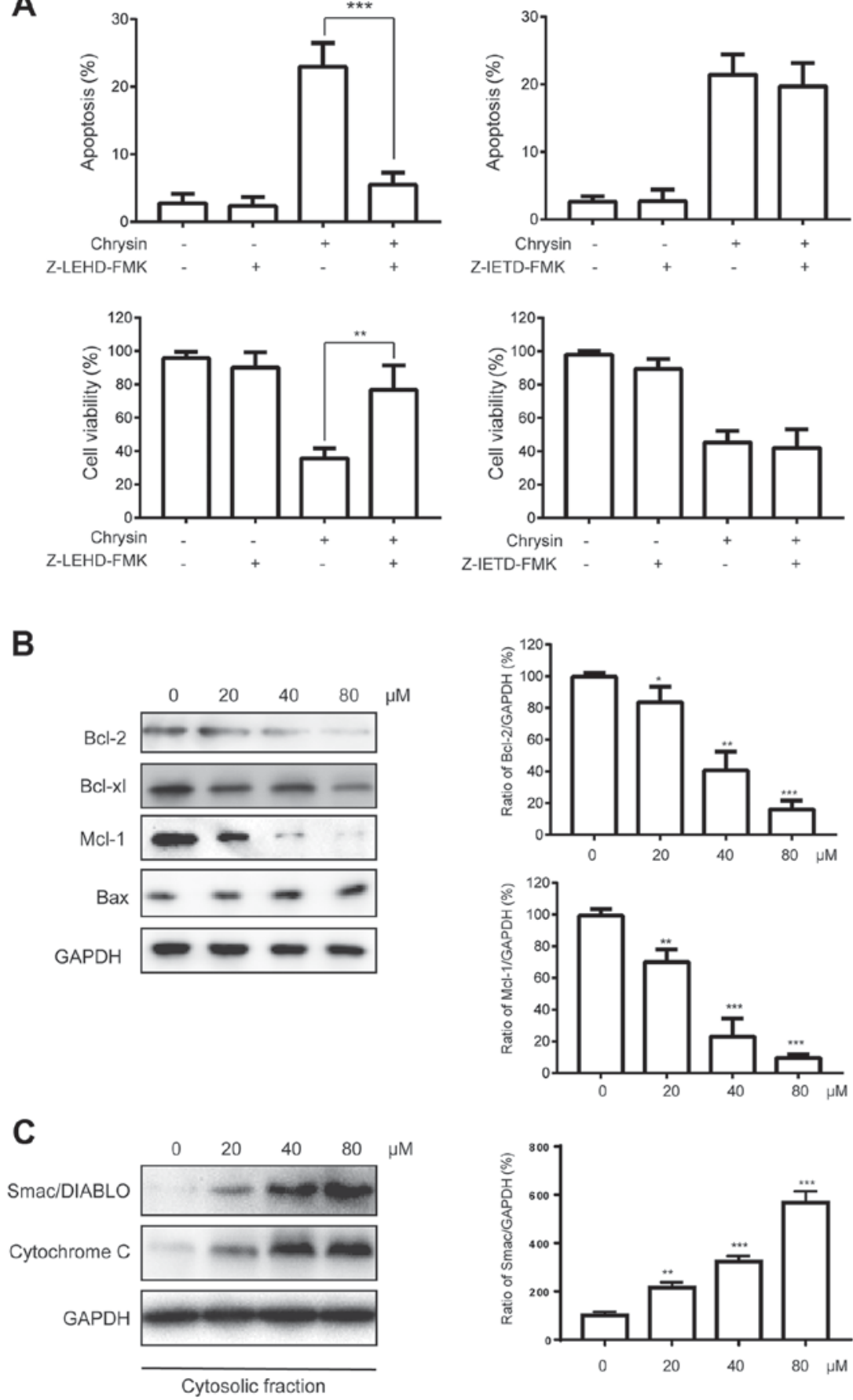
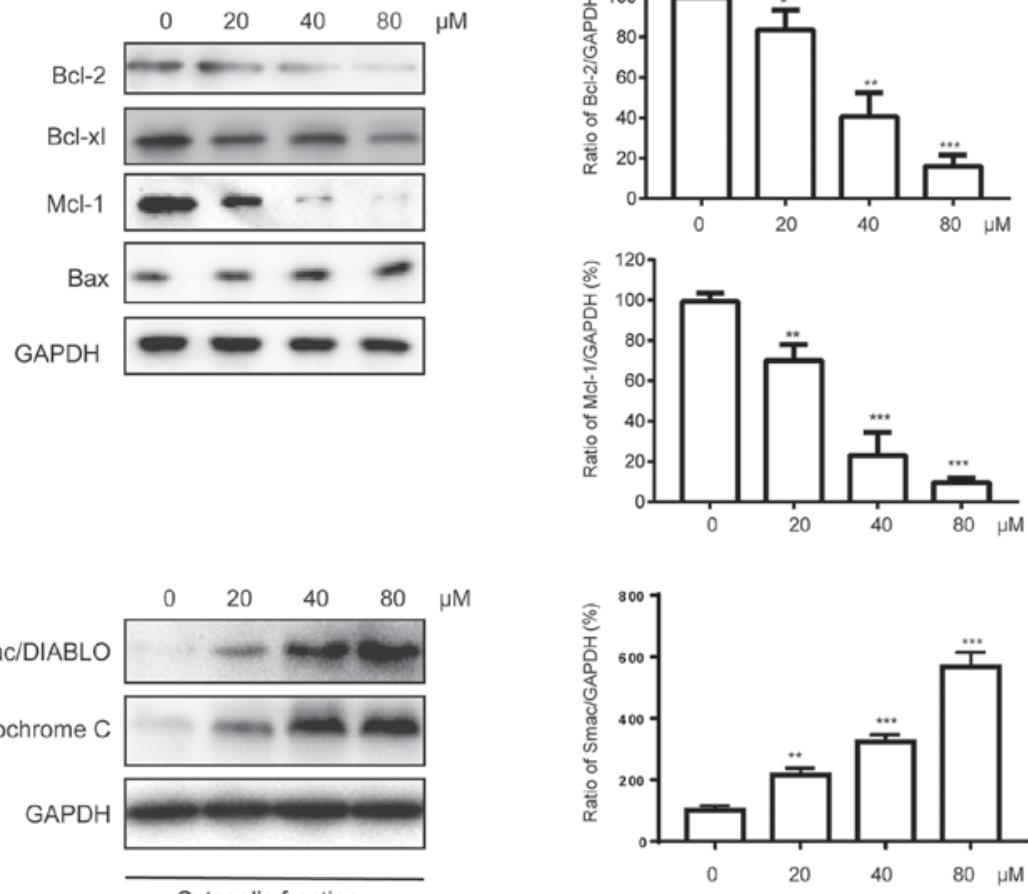
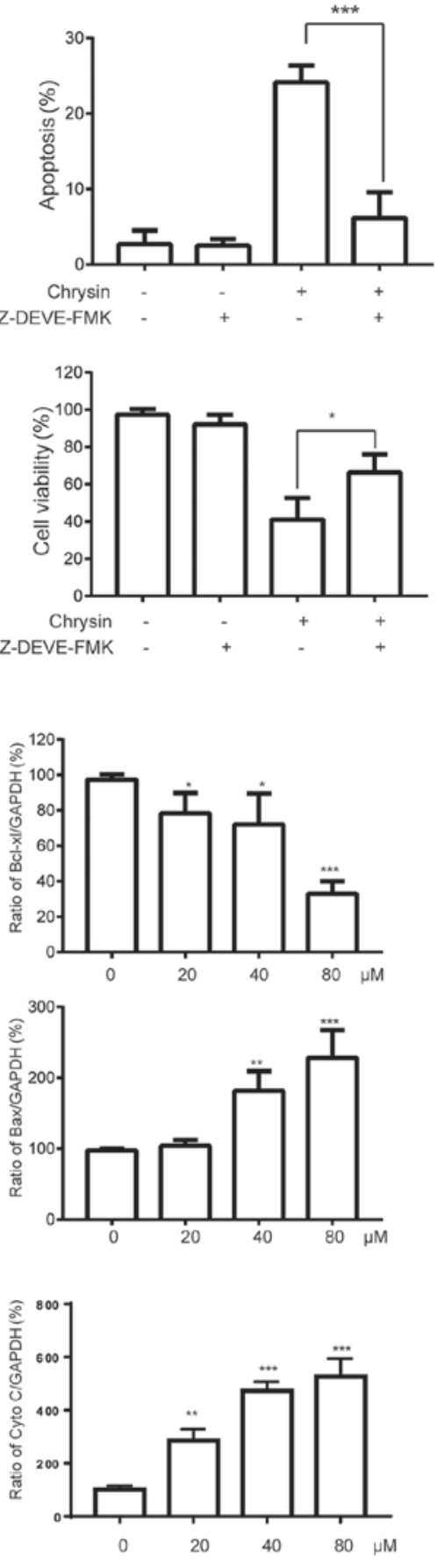

Figure 3. Chrysin induces apoptosis via the intrinsic pathway in bladder cancer cells. (A) Human bladder cancer cells T24 were treated with or without chrysin $(80 \mu \mathrm{M})$ in combination with different caspase inhibitors (Z-LEHD-FMK, Z-IETD-FMK, Z-DEVD-FMK) for 24 h, then cellular apoptosis and viability were measured with flow cytometry and MTT assay, respectively. (B) Human bladder cancer cells T24 were treated with various doses ( 0 , $20,40,80 \mu \mathrm{M})$ of chrysin for $24 \mathrm{~h}$, and then cellular lysates were subjected to western blot. (C) Human bladder cancer cells T24 and SV-HUC-1 cells were treated with various doses $(0,20,40,80 \mu \mathrm{M})$ of chrysin for $24 \mathrm{~h}$, then cellular cytosolic fractions were subjected to western blot analysis. The band densities of western blots were quantitatively analyzed. Data are presented as the mean $\pm \mathrm{SD}(\mathrm{n}=3) .{ }^{*} \mathrm{P}<0.05,{ }^{* *} \mathrm{P}<0.01,{ }^{* * *} \mathrm{P}<0.001$ vs. control.

$(80 \mu \mathrm{M})$ in the presence of the ROS scavenger NAC $(20 \mu \mathrm{M})$ and then assessed intracellular ROS production. As shown in Fig. 5A and B, NAC abolished chrysin-induced ROS generation. To further characterize the role of ROS, we examined the ER stress markers p-STAT3 and Bcl-2 by western blot. We found that NAC could block the up-regulated expression of p-PERK, p-EIF2 $\alpha$ and ATF4. In addition, NAC could abrogate the effects of chrysin on p-STAT3 and $\mathrm{Bcl}-2$ family proteins. (Fig. 5C and D). Finally, NAC also abolished the effects of chrysin on the cell viability and apoptosis (Fig. 5E and F). Altogether, ROS generation appears to play an essential role in the antitumor effects of chrysin.

\section{Discussion}

Bladder cancer continues to be a global health problem. The most common approach for treating early stage bladder cancer is surgical resection, and chemotherapy is critical for 
A
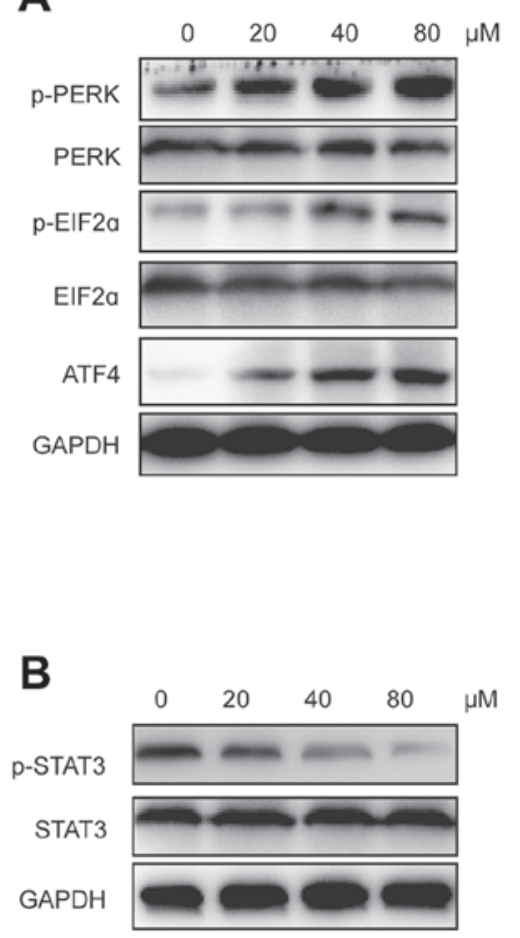
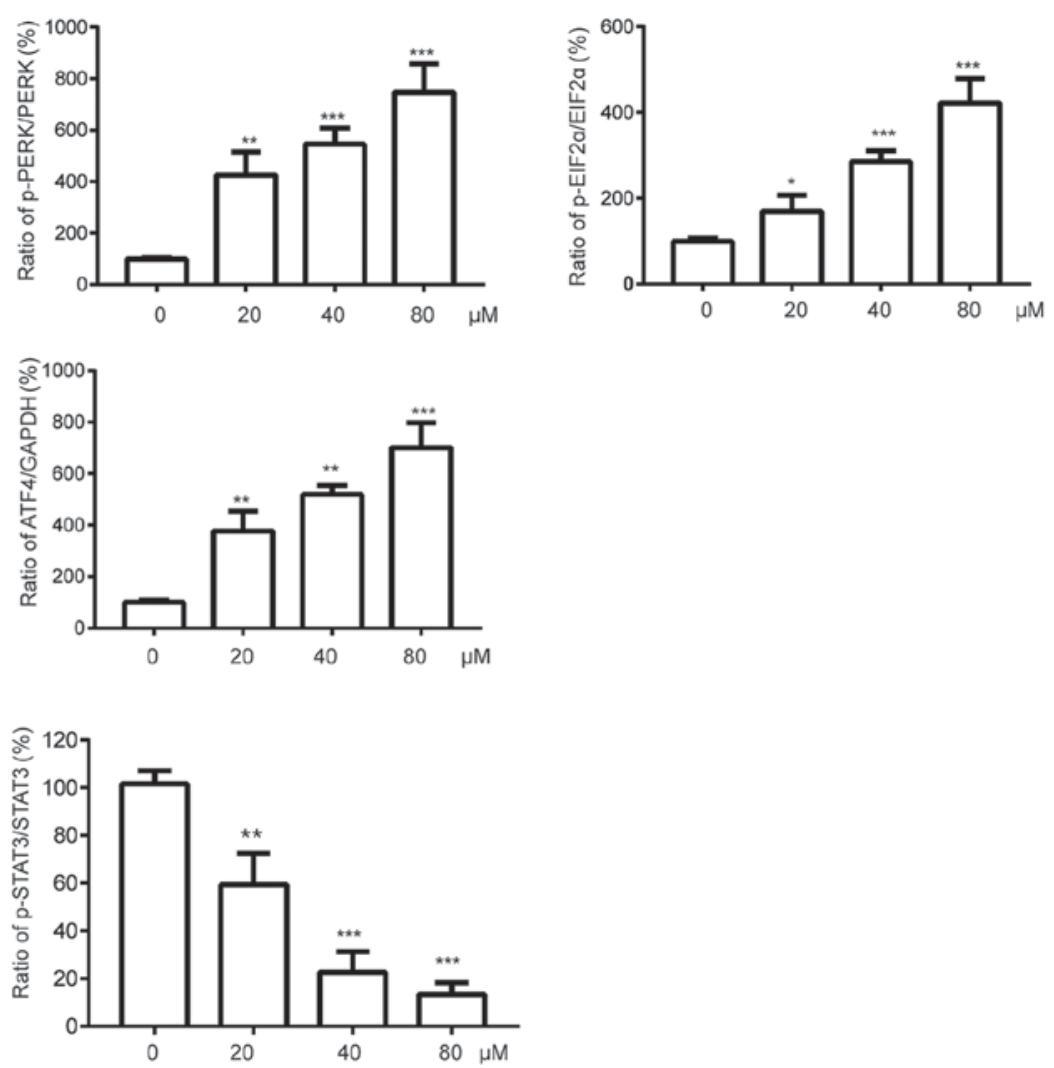

Figure 4. Chrysin induces ER stress and represses STAT3 activation. (A and B) Human bladder cancer cells T24 were treated with various doses ( $0,20,40$, $80 \mu \mathrm{M})$ of chrysin for $24 \mathrm{~h}$, then cellular lysates were subjected to western blot. The band densities of western blots were quantitatively analyzed. Data are presented as the mean $\pm \mathrm{SD}(\mathrm{n}=3) .{ }^{*} \mathrm{P}<0.05,{ }^{* *} \mathrm{P}<0.01,{ }^{* * * *} \mathrm{P}<0.001$ vs. control.

the eradication of tumors that cannot be removed by surgery. Although several chemotherapeutic agents for the management of bladder cancer have been developed in clinics, drug resistance and side effects remain pivotal issues (3). Natural products have been found to be valuable sources of antitumor agents with reduced side effects. A wide variety of natural products, such as atractylenolide I, curcumin, quercetin and fucoidan, possess significant cytotoxic activity against bladder cancer cells (21-24). Chrysin is a flavonoid found in many plant extracts and possesses various bioactivities, including a potential antitumor effect in multiple types of human cancers (11). However, little is known about the effects of chrysin on bladder cancer cells. In the present study, we found that chrysin shows promising antitumor effects against bladder cancer cells in vitro. This finding is verified by the following evidence: i) chrysin represses the viability of bladder cancer cells but not normal cells; ii) chrysin induces apoptosis in bladder cancer cells; iii) chrysin induces ER stress and inhibits STAT3 signaling in bladder cancer cells; and iv) chrysin exerts an antitumor effect via the induction of ROS.

In the present study, we discover that chrysin selectively induces the suppression of bladder cancer cell growth in a dose-dependent manner but did not reduce viability in the normal immortalized urothelial SV-HUC-1 cells. Similarly, it has been previously reported that non-transformed cells from different origins, such as fibroblasts and epithelial cells, are much more resistant to the cytotoxic effect of chrysin than malignant cells $(25,26)$. These findings indicate the selective antitumor effect of chrysin in targeting malignant cells and sparing non-cancer cells.
It is well known that apoptosis plays an essential role in the antitumor effects of chemotherapeutic agents. The activation of caspases, a group of cysteine proteases, is a key intracellular event in apoptosis. In the present study, we found that chrysin treatment promoted the activation of caspase- 3 and caspase- 9 but not caspase- 8 in T24 cells. Moreover, specific inhibitors of caspase-3/9 but not of caspase- 8 could block the antitumor effect of chrysin. We also found that the anti-apoptotic proteins Bcl-2, Bcl-xl, and Mcl-1 were repressed and that the pro-apoptotic protein Bax was upregulated after chrysin treatment. These findings indicate that chrysin selectively induces apoptosis in bladder cancer cells via the intrinsic apoptotic pathway. Our findings are similar to previous studies. For example, chrysin induced apoptosis in human lung cancer cells by activating caspase-3/9, decreasing Bcl-2 and increasing Bax (27). In a recent study, chrysin was also found to induce apoptosis in hepatocellular carcinoma cells via the intrinsic apoptotic pathway and regulation of $\mathrm{Bcl}-2$ family proteins (28). Interestingly, many other flavonoids such as quercetin, chalcone and hesperetin exert their antitumor effects by triggering intrinsic apoptosis (29-31).

Another important finding from our study was that chrysin activated the ER stress pathway in bladder cancer cells, as evidenced by increased levels of p-PERK, p-eIF2 $\alpha$ and ATF4. Phosphorylation of PERK is one of the early events in ER stress. Activated PERK directly phosphorylates eIF-2 $\alpha$ which results in the repression of eIF- $2 \alpha$. On the other hand, eIF- $2 \alpha$ increases the translation of ATF4. These findings are similar to a recent study in which chrysin also induced ER stress 
A

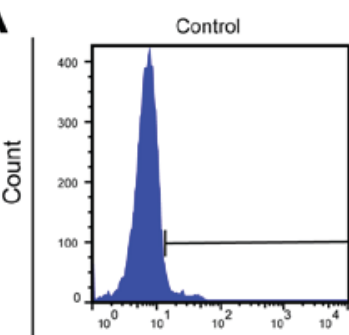

$20 \mu \mathrm{M}$

$40 \mu \mathrm{M}$
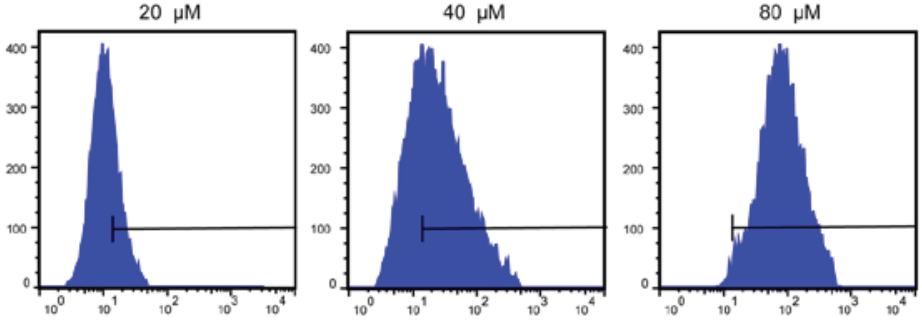

Chrysin $(80 \mu \mathrm{M})+\operatorname{NAC}(20 \mu \mathrm{M})$

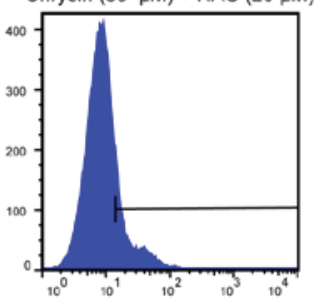

DCF-DA

B

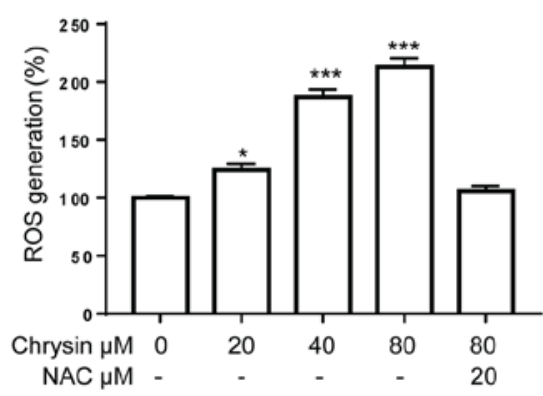

C

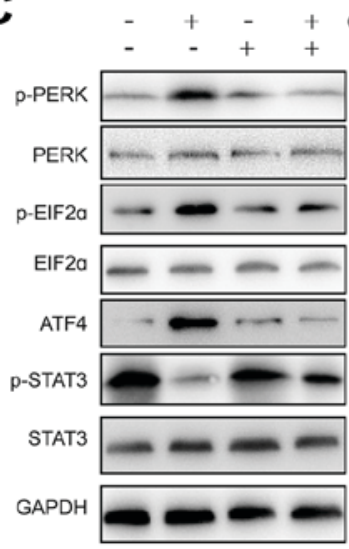

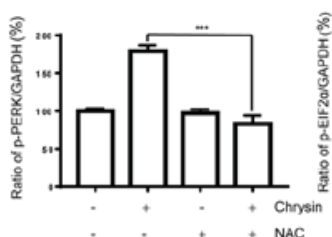
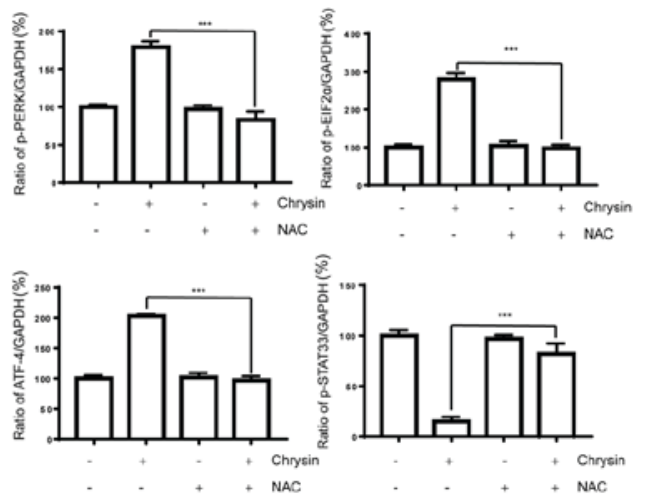

D
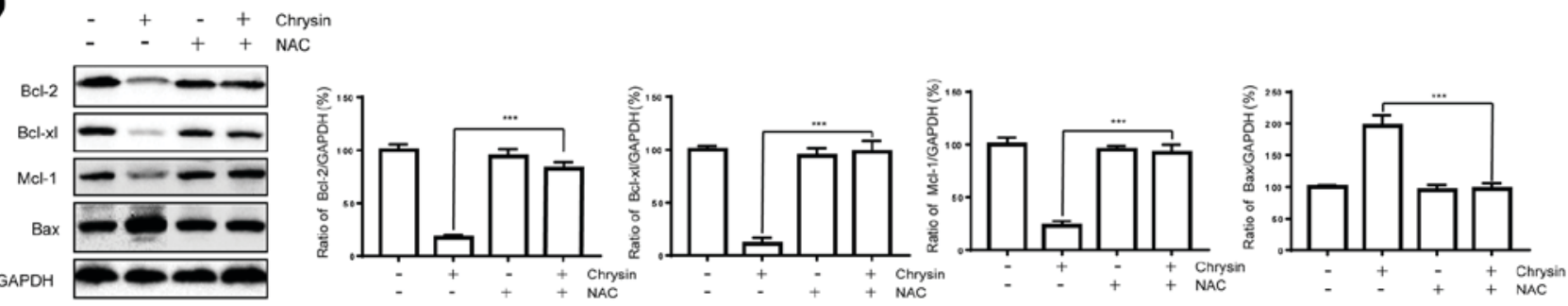

E

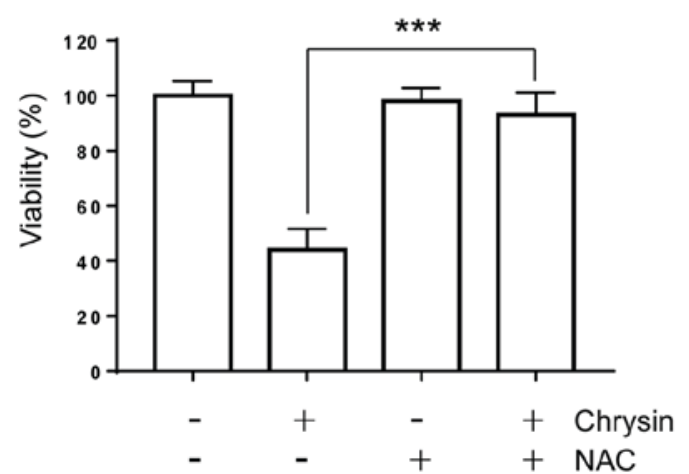

$\mathbf{F}$

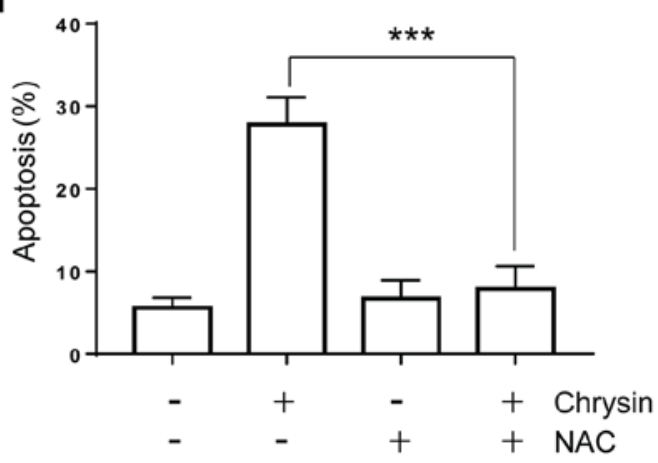

Figure 5. Antitumor effects of chrysin rely on the generation of ROS. (A and B) T24 cells were treated with various concentrations of chrysin ( $20,40,80 \mu \mathrm{M}$ ) or with NAC $(20 \mu \mathrm{M})$. Intracellular ROS generation was measured using the DCFH-DA probe with flow cytometry. M reflects the positive DCF fluorescence. (C and D) T24 cells were treated with chrysin $(80 \mu \mathrm{M})$ and NAC $(20 \mu \mathrm{M})$ for $24 \mathrm{~h}$. Then, cell lysates were subjected to western blot analysis with the indicated antibodies. The band densities of western blots were quantitatively analyzed. (E and F) T24 cells were pretreated with treated with chrysin ( $80 \mu \mathrm{M}$ ) and NAC $(20 \mu \mathrm{M})$ for $24 \mathrm{~h}$. Then, cell viability and apoptosis rate were evaluated. Data are presented as the mean $\pm \mathrm{SD}(\mathrm{n}=3)$. ${ }^{*} \mathrm{P}<0.05$ and ${ }^{* * *} \mathrm{P}<0.001 \mathrm{vs}$. control. $\mathrm{NAC}$, $\mathrm{N}$-acetyl cysteine; ROS, reactive oxygen species.

in prostate cancer cells (32). Targeting ER stress is a useful strategy against various tumors and our findings provide further insight into the antitumor effects of chrysin.

STAT3 belongs to a family of cytosolic transcription factors that are involved in cell proliferation, migration and differentiation (33). Constitutive activation of STAT3 has been implicated in various human cancers, including bladder cancer (33). Inhibition of constitutively phosphorylated STAT3 leads to growth inhibition and apoptosis of tumor cells both in vitro and in vivo (33). Interestingly, chrysin has been reported to overcome resistance to TRAIL, a TNF superfamily member that can selectively induce apoptosis in tumor cells but not normal cells, via inhibition of STAT3 phosphorylation (34). Therefore, modulation of STAT3 may 
account for the antitumor effects of chrysin, and this property may be applied to inhibit STAT3 activation in other carcinomas as well.

ROS are highly reactive oxygen free radicals and trigger multiple cellular responses including ER stress and apoptosis (35). Increasing evidence indicates that excessive oxidative stress could be used to eliminate tumor cells (36). Natural chemicals with the ability to generate ROS, such as costunolide, pachymic acid and baicalein, have demonstrated potential antitumor effects in bladder cancer cells (37-39). Herein, increased ROS production was also detected in the chrysin-treated T24 cells. Importantly, abrogation of ROS generation by NAC completely reversed the chrysin-induced ER stress, inhibition of p-STAT3 and apoptosis, suggesting an essential role of ROS in the antitumor effects of chrysin.

In summary, we studied the antitumor effects of chrysin and the potential underlying mechanism of this effect. We found that chrysin repressed cell viability and induced the intrinsic pathway of apoptosis, the activation ER stress and the modulation of STAT3 activity. Moreover, the antitumor effects of chrysin rely on the generation of ROS. These results are encouraging, although still preliminary and further investigation into how chrysin actions is needed. Our findings indicate that chrysin possesses great potential as a promising candidate for the treatment of bladder cancer.

\section{References}

1. Siegel RL, Miller KD and Jemal A: Cancer statistics, 2016. CA Cancer J Clin 66: 7-30, 2016.

2. Arantes-Rodrigues R, Pinto-Leite R, Fidalgo-Goncalves L, Palmeira C, Santos L, Colaço A and Oliveira P: Synergistic effect between cisplatin and sunitinib malate on human urinary bladder-cancer cell lines. Biomed Res Int 2013: 791406, 2013.

3. Nguyen DP and Thalmann GN: Contemporary update on neoadjuvant therapy for bladder cancer. Nat Rev Urol 14: 348-358, 2017.

4. Pratheeshkumar P, Son YO, Korangath P, Manu KA and Siveen KS: Phytochemicals in cancer prevention and therapy. Biomed Res Int 2015: 324021, 2015.

5. Parajuli P, Joshee N, Rimando AM, Mittal S and Yadav AK: In vitro antitumor mechanisms of various Scutellaria extracts and constituent flavonoids. Planta Med 75: 41-48, 2009.

6. Gresa-Arribas N, Serratosa J, Saura J and Sola C: Inhibition of CCAAT/enhancer binding protein delta expression by chrysin in microglial cells results in anti-inflammatory and neuroprotective effects. J Neurochem 115: 526-536, 2010.

7. Torres-Piedra M, Ortiz-Andrade R, Villalobos-Molina R, Singh N, Medina-Franco JL, Webster SP, Binnie M, Navarrete-Vázquez G and Estrada-Soto S: A comparative study of flavonoid analogues on streptozotocin-nicotinamide induced diabetic rats: Quercetin as a potential antidiabetic agent acting via 11beta-hydroxysteroid dehydrogenase type 1 inhibition. European journal of medicinal chemistry 45: 2606-2612, 2010.

8. Wang J, Qiu J, Dong J, Li H, Luo M, Dai X, Zhang Y, Leng B, Niu X, Zhao S and Deng X: Chrysin protects mice from staphylococcus aureus pneumonia. J Appl Microbiol 111: 1551-1558, 2011.

9. Du Q, Gu X, Cai J, Huang M and Su M: Chrysin attenuates allergic airway inflammation by modulating the transcription factors T-bet and GATA-3 in mice. Mol Med Rep 6: 100-104, 2012.

10. Huang C, Wei YX, Shen MC, Tu YH, Wang CC and Huang HC: Chrysin, abundant in morinda citrifolia fruit water-etoac extracts, combined with apigenin synergistically induced apoptosis and inhibited migration in human breast and liver cancer cells. J Agric Food Chem 64: 4235-4245, 2016.

11. Kasala ER, Bodduluru LN, Madana RM, V AK, Gogoi R and Barua CC: Chemopreventive and therapeutic potential of chrysin in cancer: Mechanistic perspectives. Toxicol Lett 233: 214-225, 2015.
12. Yu R, Deedigan L, Albarenque SM, Mohr A and Zwacka RM: Delivery of STRAIL variants by MSCs in combination with cytotoxic drug treatment leads to p53-independent enhanced antitumor effects. Cell Death Dis 4: e503, 2013.

13. Baig S, Seevasant I, Mohamad J, Mukheem A, Huri HZ and Kamarul T: Potential of apoptotic pathway-targeted cancer therapeutic research: Where do we stand? Cell Death Dis 7: e2058, 2016.

14. Singh MP, Han J and Kang SC: 3',5-dihydroxy-3,4',7-trimethoxyflavone-induces ER-stress-associated HCT-116 programmed cell death via redox signaling. Biomed Pharmacothe 88: 151-161, 2017.

15. Lin CC, Kuo CL, Lee MH, Lai KC, Lin JP, Yang JS, Yu CS, Lu CC, Chiang JH, Chueh FS and Chung JG: Wogonin triggers apoptosis in human osteosarcoma U-2 OS cells through the endoplasmic reticulum stress, mitochondrial dysfunction and caspase-3-dependent signaling pathways. Int J Oncol 39: 217-224, 2011.

16. Bhardwaj M, Kim NH, Paul S, Jakhar R, Han J and Kang SC: 5-hydroxy-7-methoxy flavone triggers mitochondrial-associated cell death via reactive oxygen species signaling in human colon carcinoma cells. PloS one 11: e0154525, 2016.

17. Harding HP, Zhang Y and Ron D: Protein translation and folding are coupled by an endoplasmic-reticulum-resident kinase. Nature 397: 271-274, 1999.

18. Shi Y, Vattem KM, Sood R, An J, Liang J, Stramm L and Wek RC: Identification and characterization of pancreatic eukaryotic initiation factor 2 alpha-subunit kinase, PEK, involved in translational control. Mol Cell Biol 18: 7499-7509, 1998.

19. Harding HP, Zhang Y, Zeng H, Novoa I, Lu PD, Calfon M, Sadri N, Yun C, Popko B, Paules R, et al: An integrated stress response regulates amino acid metabolism and resistance to oxidative stress. Molecular cell 11: 619-633, 2003.

20. Aggarwal BB and Shishodia S: Molecular targets of dietary agents for prevention and therapy of cancer. Biochem Pharmacol 71: 1397-1421, 2006.

21. Yu R, Yu BX, Chen JF, Lv XY, Yan ZJ, Cheng Y and Ma Q: Anti-tumor effects of Atractylenolide I on bladder cancer cells. J Exp Clin Cancer Res 35: 40, 2016.

22. Tong QS, Zheng LD, Lu P, Jiang FC, Chen FM, Zeng FQ, Wang L and Dong JH: Apoptosis-inducing effects of curcumin derivatives in human bladder cancer cells. Anticancer Drugs 17: 279-287, 2006.

23. Su Q, Peng M, Zhang Y, Xu W, Darko KO, Tao T, Huang Y, Tao X and Yang X: Quercetin induces bladder cancer cells apoptosis by activation of AMPK signaling pathway. Am J Cancer Res 6: 498-508, 2016.

24. Park HY, Kim GY, Moon SK, Kim WJ, Yoo YH and Choi YH: Fucoidan inhibits the proliferation of human urinary bladder cancer T24 cells by blocking cell cycle progression and inducing apoptosis. Molecules 19: 5981-5998, 2014.

25. Zhang S, Yang X and Morris ME: Flavonoids are inhibitors of breast cancer resistance protein (ABCG2)-mediated transport. Mol Pharmacol 65: 1208-1216, 2004.

26. Cardenas M, Marder M, Blank VC and Roguin LP: Antitumor activity of some natural flavonoids and synthetic derivatives on various human and murine cancer cell lines. Bioorg Med Chem 14: 2966-2971, 2006.

27. Samarghandian S, Nezhad MA and Mohammadi G: Role of caspases, Bax and Bcl-2 in chrysin-induced apoptosis in the A549 human lung adenocarcinoma epithelial cells. Anticancer Agents Med Chem 14: 901-909, 2014.

28. Zhang Q, Ma S, Liu B, Liu J, Zhu R and Li M: Chrysin induces cell apoptosis via activation of the p53/Bcl-2/caspase-9 pathway in hepatocellular carcinoma cells. Exp Ther Med 12: 469-474, 2016.

29. Srivastava S, Somasagara RR, Hegde M, Nishana M, Tadi SK, Srivastava M, Choudhary B and Raghavan SC: Quercetin, a natural flavonoid interacts with dna, arrests cell cycle and causes tumor regression by activating mitochondrial pathway of apoptosis. Sci Rep 6: 24049, 2016.

30. Ramirez-Tagle R, Escobar CA, Romero V, Montorfano I, Armisén R, Borgna V, Jeldes E, Pizarro L, Simon F and Echeverria C: Chalcone-induced apoptosis through caspase-dependent intrinsic pathways in human hepatocellular carcinoma cells. Int J Mol Sci 17: 260, 2016.

31. Wu D, Zhang J, Wang J, Li J, Liao F and Dong W: Hesperetin induces apoptosis of esophageal cancer cells via mitochondrial pathway mediated by the increased intracellular reactive oxygen species. Tumour Biol 37: 3451-3459, 2016. 
32. Ryu S, Lim W, Bazer FW and Song G: Chrysin induces death of prostate cancer cells by inducing ROS and ER stress. J Cell Physiol 232: 3786-3797, 2017.

33. Yu H, Lee H, Herrmann A, Buettner R and Jove R: Revisiting STAT3 signalling in cancer: New and unexpected biological functions. Nat Rev Cancer 14: 736-746, 2014.

34. Lirdprapamongkol K, Sakurai H, Abdelhamed S, Yokoyama S, Athikomkulchai S, Viriyaroj A, Awale S, Ruchirawat S, Svasti J and Saiki I: Chrysin overcomes TRAIL resistance of cancer cells through Mcl-1 downregulation by inhibiting STAT3 phosphorylation. Int J Oncol 43: 329-337, 2013.

35. Redza-Dutordoir M and Averill-Bates DA: Activation of apoptosis signalling pathways by reactive oxygen species. Biochim Biophys Acta 1863: 2977-2992, 2016.

36. Moloney JN and Cotter TG: ROS signalling in the biology of cancer. Semin Cell Dev Biol: 30383-30384, 2017.

37. Choi EO, Park C, Hwang HJ, Hong SH, Kim GY, Cho EJ, Kim WJ and Choi YH: Baicalein induces apoptosis via ROS-dependent activation of caspases in human bladder cancer 5637 cells. Int J Oncol 49: 1009-1018, 2016
38. Rasul A, Bao R, Malhi M, Zhao B, Tsuji I, Li J and Li X: Induction of apoptosis by costunolide in bladder cancer cells is mediated through ROS generation and mitochondrial dysfunction. Molecules 18: 1418-1433, 2013.

39. Jeong JW, Lee WS, Go SI, Nagappan A, Baek JY, Lee JD, Lee SJ, Park C, Kim GY and Kim HJ: Pachymic acid induces apoptosis of EJ bladder cancer cells by DR5 Up-regulation, ROS generation, modulation of Bcl-2 and IAP family members. Phytother Res 29: 1516-1524, 2015.

cc) (7) (8) This work is licensed under a Creative Commons Attribution 4.0 International (CC BY-NC 4.0) License 